\author{
Final Report \\ DE-FG07-02ID14326

\section{Insulation for a Thermionic Microbattery} \\ Professor James P. Blanchard \\ Department of Engineering Physics \\ University of Wisconsin \\ 1500 Engineering Dr. \\ Madison, WI 53706 \\ (608) 263-0391 \\ (608) 263-7451 (FAX) \\ blanchard@engr.wisc.edu \\ http://www.engr.wisc.edu/ep/faculty/blanchard_james.html
}

Subcontractor: Sandia National Laboratory 


\section{Summary of Proposed Work}

Microelectromechanical Systems (MEMS) have not gained wide use because they lack the on-device power required by many important applications. To supply this needed power, one can consider power from fossil fuels, but nuclear sources provide an intriguing option in terms of power density and lifetime. In order to make use of alpha particles, one is forced to use thermal approaches because diodes are damaged by the high energy of the alphas. One difficulty, though, is that the surface to volume ratio increases as we move to smaller scales and heat losses thus become significant at MEMS scales. Hence, efficient microscale insulation is needed to permit high overall efficiencies. This research explores concepts for one variety of microscale insulation created using MEMS fabrication techniques.

The preliminary design for the micro-insulation is shown schematically in the figure below. The focus of the design is a GaAs wafer that is approximately $0.625 \mathrm{~mm}$ thick and $70 \mathrm{~mm}$ in diameter. A $100 \mathrm{~nm}$ epitaxial layer of AlAs followed by a $2000 \mathrm{~nm}$ layer of GaAs is then deposited. The AlAs layer serves as an etch stop. A membrane of GaAs is created by jet etching from the back of the wafer using a gold mask. The jet etchant stops at the AlAs layer, which is then removed in dilute HF. The GaAs membrane is coated with a high-reflection (HR) coating. Underneath this layer is a high reflectivity coating. Suspended above the GaAs wafer by the GaAs spikes is a silicon wafer with a highly reflective coating. These spikes minimize the contact area and thus minimize conduction losses.

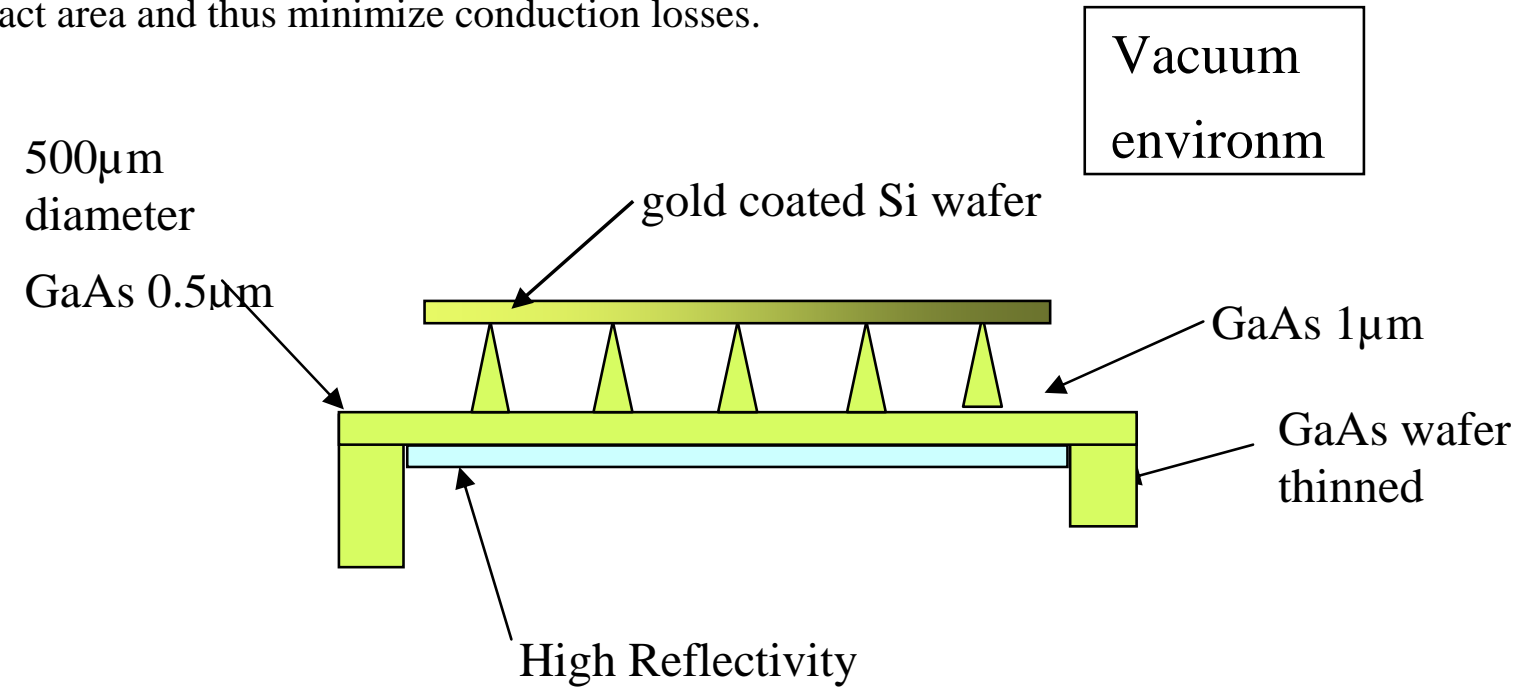

Figure 1: Preliminary design for microinsulation

\section{Fabrication}


The fabrication of a test article at Sandia National Laboratories' Compound Semiconductor Research Laboratory (CSRL) is underway. The developmental stages were as follows:

- A decision was made to produce test articles in two stages. The first test article consists of chips with trial productions of spike layers. The second test article will include the spike layer, a thinned membrane, and a reflective coating. An analysis was completed to determine a range of spacings between spikes for testing.

- A quarter-wafer mask was fabricated for the spike-layer test articles. The pattern for the quarter-wafer is shown in Figure 2. The first number in each box refers to the bottom diameter of each spike (1/2 or 1 micron). The second number refers to the spacing between spikes (10 50 or 100 microns. Each spike is 1 micron tall. The $3 \mathrm{~mm} \times 3 \mathrm{~mm}$ boxes represent the area covered by each set of spikes. The pitch between patterned areas is $5 \mathrm{~mm}$.

- Several trial runs were made to determine the appropriate method for fabricating spikes using a new type of etching equipment. After several trials, an acceptable method was established, and the test articles were fabricated, as shown in the micrographs in Figure 3.

- The MHB spike-layer test articles were passed to the University of Wisconsin for testing.

- Fabrication of the membrane for the next set of test particles began. A GaAs wafer was grown with a wet etch stop layer and 2 microns of GaAs to serve as a membrane. 


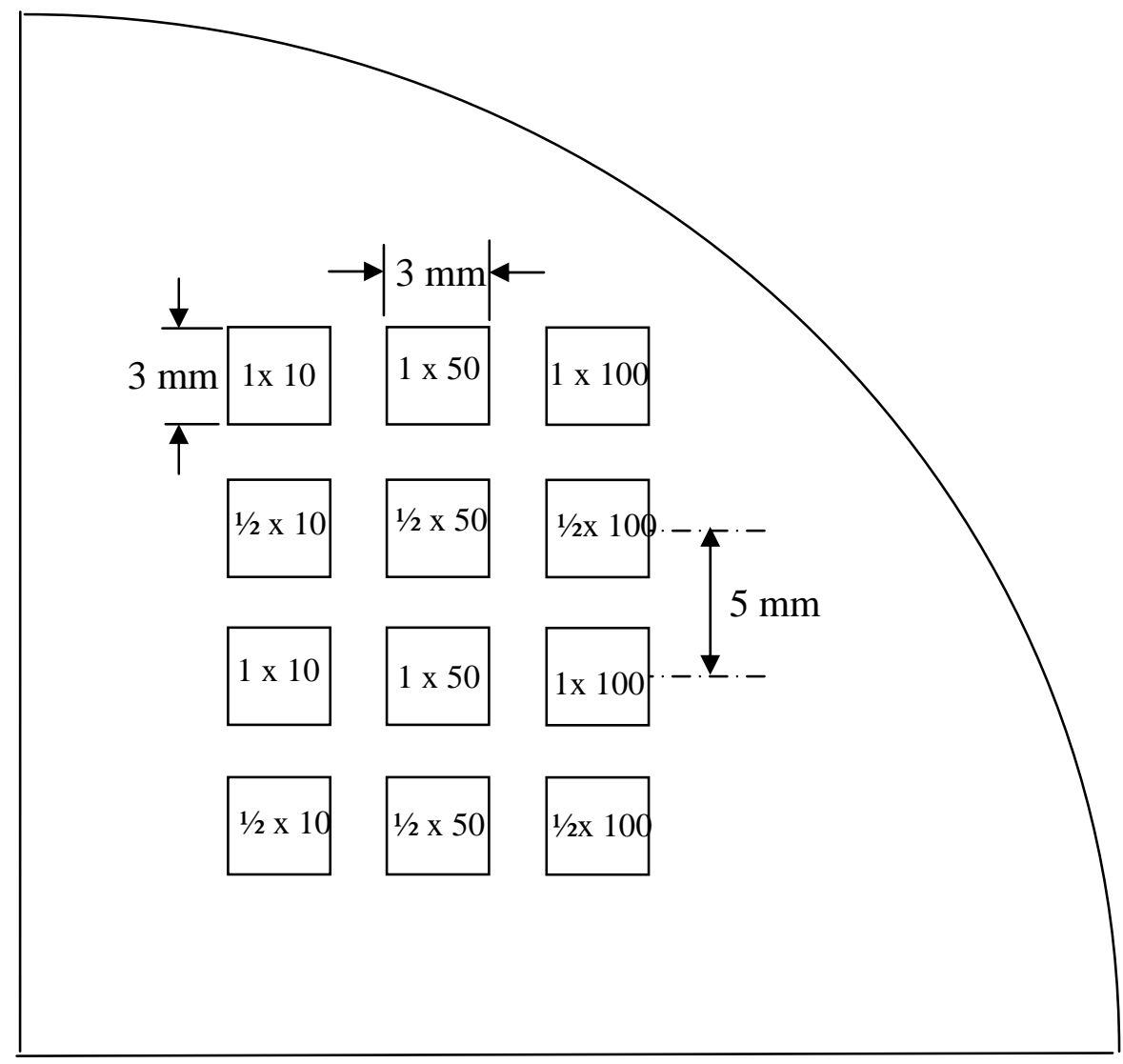

Figure 2 Patterned MHB 1/4 Wafer 

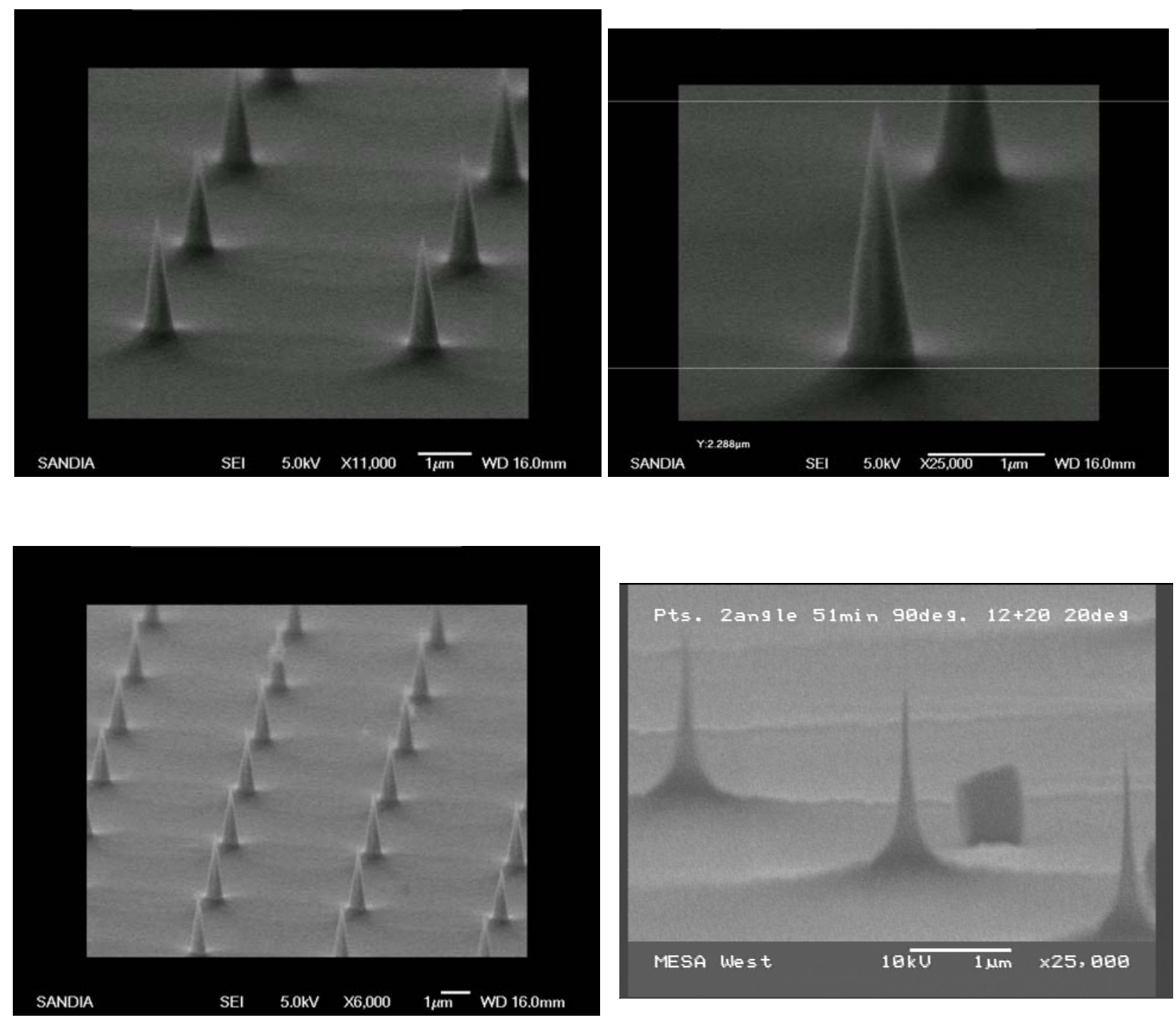

Figure 3 Micro Heat Barrier spike etches.

\section{Modeling of Insulation}

Maximum Displacement in a Circular Plate

One key design parameter is the spacing of the cones supporting one surface of the micro heat barrier (MHB) above the other. These cones must be far enough apart to reduce conduction 
through them relative to radiation from surface to surface, but they must be close enough to prevent the upper surface from collapsing. We will first address the support issue, modeling the upper surface as a circular plate with the diameter approximately equal to the cone spacing. The edges of this plate are modeled as simply supported in one case, and clamped in a second case. The load is from the weight of the plate and the maximum displacement $\delta_{\max }$ occurs at the center. We take the displacement limit to be approximately the plate spacing (1 micron).

For a simply supported edge and uniform load ${ }^{1}$,

$$
\delta_{\max }=\frac{3}{16}(1-v)(5+v) \frac{w R^{4}}{E t^{3}}
$$

where $v$ is Poisson's ratio, $\mathrm{w}$ is uniform load per unit area, $\mathrm{t}$ is plate thickness, $\mathrm{R}$ is plate radius, E is elastic modulus. For fixed edge and uniform load,

$$
\delta_{\max }=\frac{3}{16}\left(1-v^{2}\right) \frac{w R^{4}}{E t^{3}}
$$

The displacements are shown in the figure below. As can be seen, the separation can be quite large. Hence, the failure mechanism is more likely collapse of the cones, rather than collapse of the upper plate.

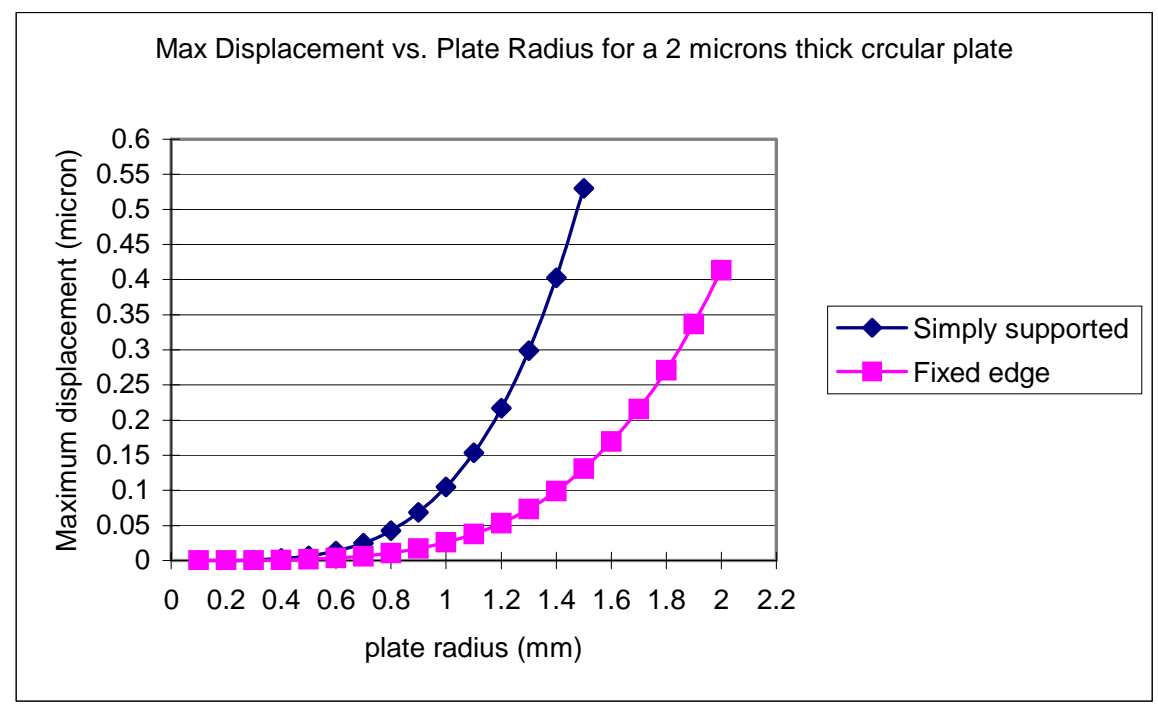

Figure 4: Maximum Displacement for a 2 micron thick circular plate 


\section{Thermal Conductivity of Air at Low Pressure}

In order to minimize conduction through the MHB, the gas pressure between the layers must be kept to a minimum. The necessary pressure can be chosen by ensuring that conduction through the gas is small compared to the radiation through it. Because the gas pressure will be quite small, macroscopic models for gas conduction are not valid and we must take care to accurately represent the conductivity. From a simple kinetic-theory model ${ }^{2}$ the thermal conductivity is

$$
k_{\text {gas }}=\frac{1}{3} \rho \bar{w} \lambda c_{v}
$$

where $\rho$ is the density, $w$ is the average molecule velocity, $\lambda$ is the mean free path of the particles in the gas, and $c_{v}$ is the heat capacity. Similarly, dynamic viscosity is

$$
\mu=\frac{1}{3} \rho \bar{w} \lambda
$$

so

$$
k_{\text {gas }}=\mu \cdot c_{v}
$$

Eucken used this relationship to account for internal degrees of freedom in the molecule

$$
k_{\text {gas }}^{\text {Eucken }}=\mu\left(c_{v}+\frac{9}{4} \frac{R}{M}\right)=\frac{1}{4}(9 \gamma-5) \mu \cdot c_{v}
$$

To find $\mu=\frac{1}{3} \rho \bar{w} \lambda$ we can use

$$
\begin{gathered}
\rho_{\text {vac }}=\rho_{\text {std }} \cdot \frac{P_{\text {vac }}}{P_{\text {std }}}=0.2947 \mathrm{~kg} / \mathrm{m}^{3} \cdot \frac{1.33 \mathrm{~Pa}}{101325 \mathrm{~Pa}}=3.87 \times 10^{-6} \mathrm{~kg} / \mathrm{m}^{3} \\
\bar{w}=\sqrt{\frac{8 R T}{\pi M}}=936 \mathrm{~m} / \mathrm{s}
\end{gathered}
$$

\footnotetext{
${ }^{1}$ Fred B. Seely, James O. Smith, Advanced Mechanics of Materials, second edition, John Wiley \& Sons, 1959

${ }^{2}$ E.R.G. Eckert, Robert M. Drake, JR., Analysis of Heat And Mass Transfer, MaGraw-Hill, 1972
} 
where $\mathrm{M}$ is molecular weight, $\mathrm{R}$ is the universal gas constant, and $\mathrm{T}$ is absolute temperature. Also, the mean free path of gaseous molecules is

$$
\lambda=\frac{1}{\sqrt{2} \pi d^{2} n} \frac{k T}{\sqrt{2} \pi d^{2} P}
$$

where $\mathrm{d}$ is the diameter of gas molecules, $\mathrm{n}$ is the number of molecules per unit volume, $\mathrm{k}$ is Boltzman constant, $\mathrm{T}$ is temperature, $\mathrm{P}$ is pressure. For air, $\mathrm{d}=2 * 10^{-10} \mathrm{~m}, \mathrm{~T}=1200 \mathrm{~K}, \mathrm{P}=10^{-2}$ Torr, $\lambda=7 \mathrm{~cm}$

$$
\begin{gathered}
\mu=8.45 * 10^{-5} \mathrm{~kg} / \mathrm{ms} \\
\mathrm{C}_{\mathrm{p}}=1.18 \mathrm{~J} / \mathrm{kgK} \text { at } 1200 \mathrm{~K} \\
c_{v}=\frac{c_{p}}{\gamma}=\frac{1.18 \mathrm{~J} / \mathrm{kg} \cdot \mathrm{K}}{1.4}=0.84 \mathrm{~J} / \mathrm{kg} \cdot \mathrm{K} \\
\mathrm{k}_{\mathrm{gas}}=1.35^{*} 10^{-4} \mathrm{~W} / \mathrm{mK}
\end{gathered}
$$

C. L. Tien ${ }^{3}$ gives another relation in terms of macroscopic properties for estimating mean free path

$$
\lambda=8.6\left(\frac{\mu}{P_{v a c}}\right) \sqrt{\frac{T}{M}}
$$

where $\mu$ is viscosity in poise, $P_{\text {vac }}$ pressure in millimeters mercury (or Torr), $\lambda$ is in centimeters. This gives about 5 times lower value than the previous result. For air, $\mathrm{d}=2 * 10^{-10} \mathrm{~m}, \mathrm{~T}=300 \mathrm{~K}$, $\mathrm{P}=10^{-2}$ Torr, $\lambda=0.75 \mathrm{~cm}$. Note here that since the mean free path is much larger than the characteristic length (four orders larger than the two-plate spacing), the mean free path bounded by the two plates is limited by the spacing dimensions. So under free-molecule conditions, the mean free path defined above must be replaced by D.

$$
\begin{gathered}
\mu=\frac{1}{3} \rho \bar{w} D=3.6 \times 10^{-9} \mathrm{~kg} / \mathrm{m} \cdot \mathrm{s} \\
\mathrm{C}_{\mathrm{p}}=1.18 \mathrm{~J} / \mathrm{kgK} \text { at } 1200 \mathrm{~K}, \text { air }
\end{gathered}
$$

\footnotetext{
${ }^{3}$ C. L. Tien, G. R. Cunnington, Cryogenic Insulation Heat Transfer, Advances in Heat Transfer, Academic Press, Inc. Vol. 9, 1973
} 


$$
C_{v}=\frac{c_{p}}{\gamma}=\frac{1.18 \mathrm{~J} / \mathrm{kg} \cdot \mathrm{K}}{1.4}=0.84 \mathrm{~J} / \mathrm{kg} \cdot \mathrm{K}
$$

Combining these equations, we find

$$
k_{\text {gas }}=\frac{1}{12}(9 \gamma-5) \frac{\rho_{\text {std }, T} P_{v a c}}{P_{\text {std }}} \sqrt{\frac{8 R T}{\pi M}} \frac{C_{p}}{\gamma} D
$$

which gives $\mathrm{k}_{\text {gas }}=5.75^{*} 10^{-9} \mathrm{~W} / \mathrm{mK}$.

The thermal conductivity of a gas under free-molecule conditions is decreased as pressure is reduced. This is because when rarefaction increases, the numbers of collisions between gaseous molecules are much less than the numbers of impacts of gaseous molecules on the solid surfaces. In other words, the gaseous molecules strike one surface, then another surface without colliding with one another. So the heat exchanged is proportional to the number of molecules striking both surfaces and consequently proportional to the pressure of the rarefied gas between the two plates.

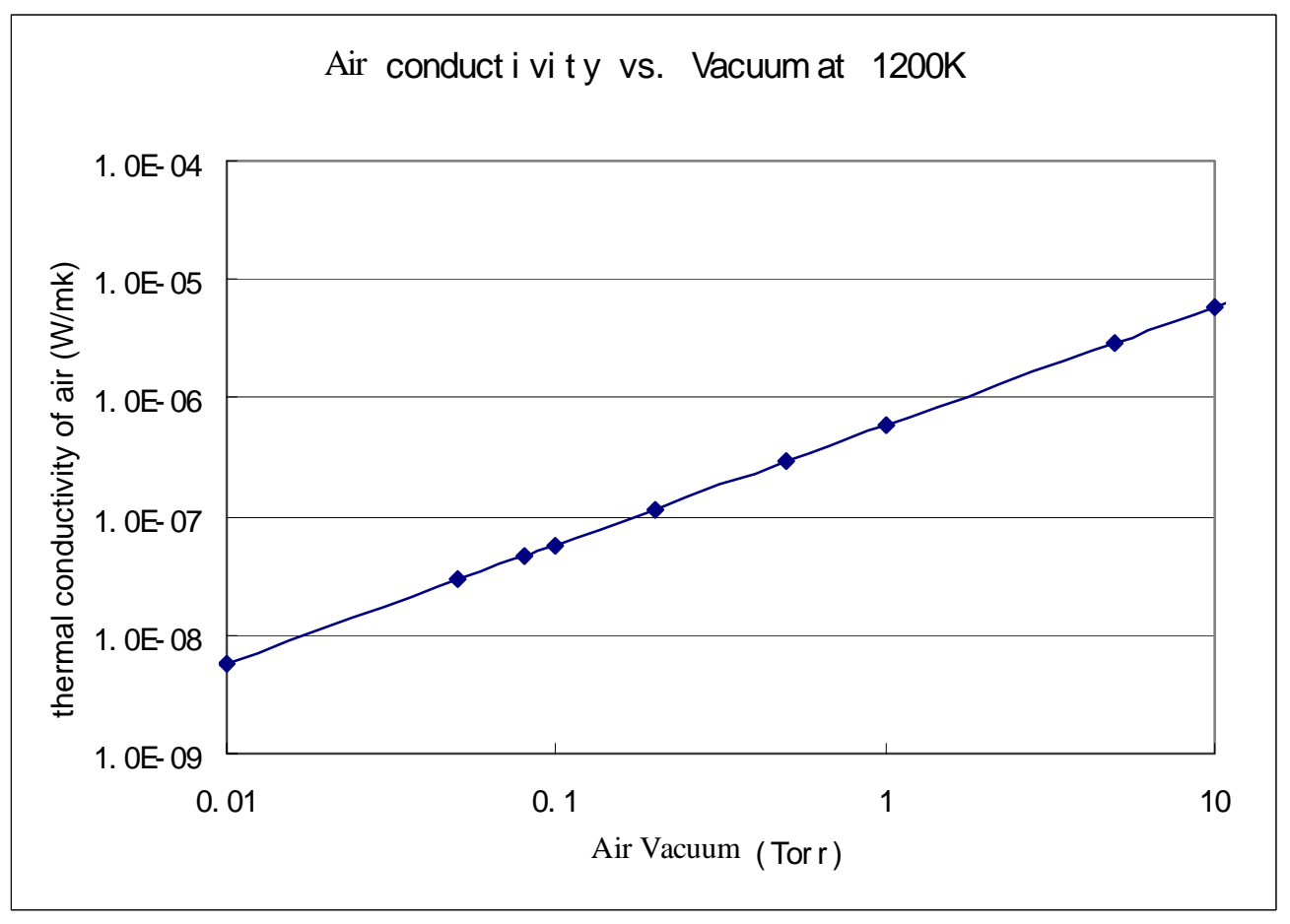

Figure 5: Thermal Conductivity of Air as a Function of Pressure 
Using the Fourier law, the heat transfer by gas conduction is given by

$$
q^{\prime \prime}=\frac{k_{\text {gas }}}{D} \Delta T=\frac{1}{12}(9 \gamma-5) \frac{\rho_{\text {std }, T} P_{v a c}}{P_{s t d}} \sqrt{\frac{8 R T}{\pi M}} \frac{C_{p}}{\gamma} \Delta T
$$

which indicates that the conductive heat flux is independent of the gap spacing $\mathrm{D}$.

The vacuum, here is also important in defining the free-molecule regime $(\mathrm{Kn}>10)$. Using this equation will give more conservative results for estimating the required vacuum to satisfy freemolecular conditions. From the graph below, assuming $\mathrm{D}$ is 3 microns, the vacuum must be lower than 5 Torr to ensure $\mathrm{Kn}>10$.

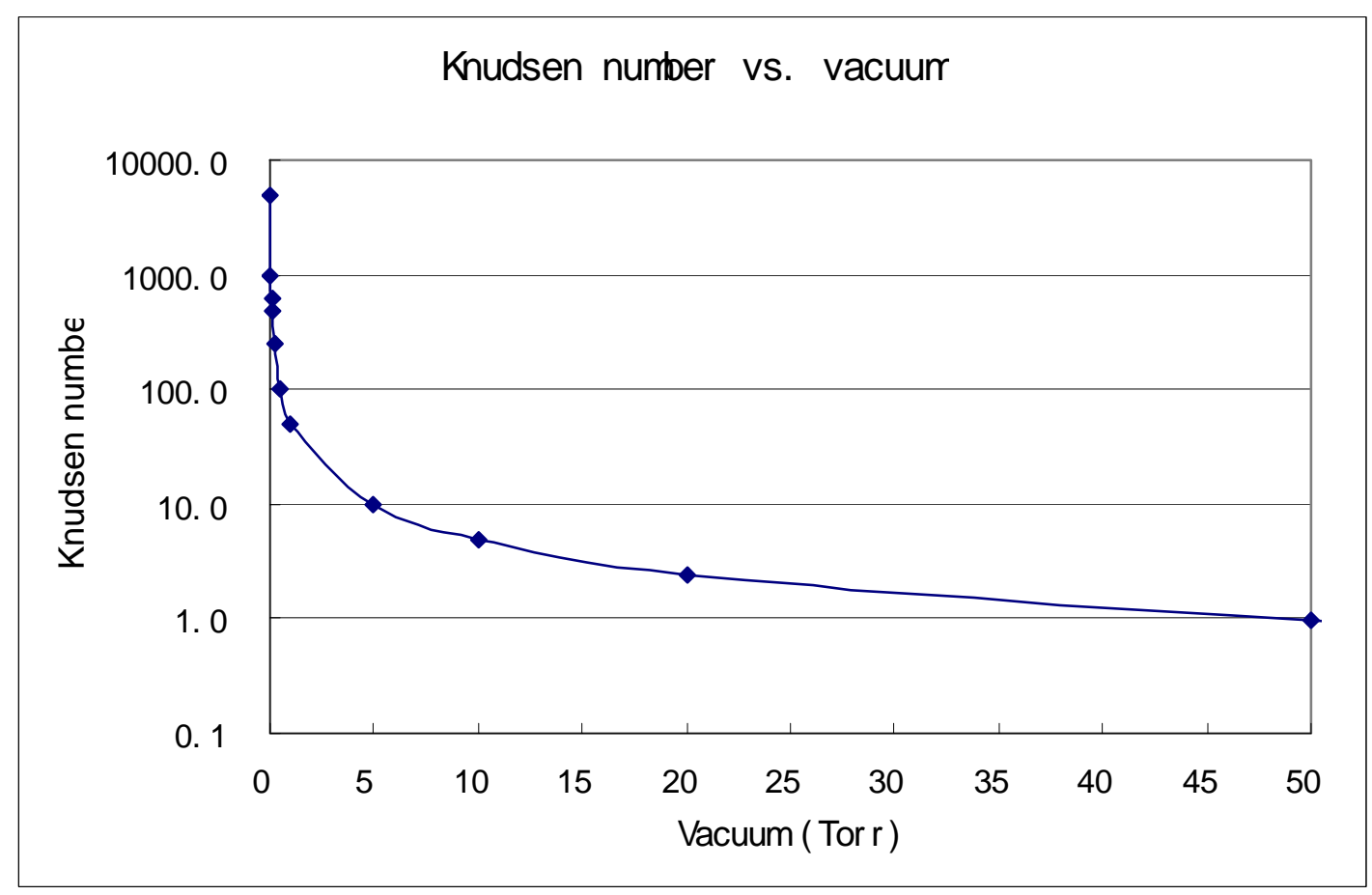

Figure 6: Knudson number for Air

\section{Heat transfer between two plates}

This thermal conductivity model can be used to assess the necessary pressure needed for efficient MHB performance. We can simultaneously assess the relative heat transfer through the 
cones and the gap between the MHB layers. When a constant and uniform heat flux Q is applied to one plate, we can assume one part of heat, $\mathrm{Q} * \mathrm{f}$, goes through the cones by conduction and the other part, Q(1-f), goes through vacuum by radiation and conduction of residue air.

Assuming the "cones" have constant cross-section, the thermal resistance of the cones is

$$
R_{s}=\frac{D}{A_{s} k}
$$

where $\mathrm{D}$ is the cone length, $\mathrm{A}_{\mathrm{s}}$ is the total cross section area of all the cones, and $\mathrm{k}$ is the thermal conductivity of GaAs. The thermal resistance of the air is

$$
R_{g}=\frac{D}{A_{g} k_{\text {gas }}}
$$

where $A_{g}$ is the total cross section of gas conduction. The thermal resistance of radiation is

$$
R_{r}=\frac{\frac{1}{\varepsilon_{1}}+\frac{1}{\varepsilon_{2}}-1}{\sigma \cdot A_{g}\left(T_{1}^{2}+T_{2}^{2}\right)\left(T_{1}+T_{2}\right)}
$$

where $\sigma$ is Stefan-Boltzman constant, $\varepsilon_{1}$ and $\varepsilon_{2}$ are emissivities of the inside surfaces of the two plates.

Using these relations, the relative heat transfer rates are given by:

$$
\begin{gathered}
Q \cdot f=\frac{T_{1}-T_{2}}{R_{s}} \\
Q \cdot(1-f)=\frac{T_{1}-T_{2}}{R_{g}+R_{r}}
\end{gathered}
$$

The total equivalent thermal conductivity of the MHB is thus

$$
k_{e q}=\frac{Q \cdot D}{\left(T_{1}-T_{2}\right)\left(A_{s}+A_{g}\right)}
$$

Consider a case where there are a certain number of cones between the two plates, with the distance between any two neighboring cones defined as L. For any single cone, the total heat transferred consists of conduction through its cross section and gas conduction and radiation 
through the area between the cones. Assuming the cone's diameter is 0.2 microns, the accommodation coefficient is $1, \mathrm{~F}$ is $1, \varepsilon_{1}$ and $\varepsilon_{2}$ are 0.9 , and the gas pressure between two plates is 5 Torr, where free-conduction condition is just satisfied, the relationship between cone distance and the heat flux fraction and overall thermal conductivity is given below.

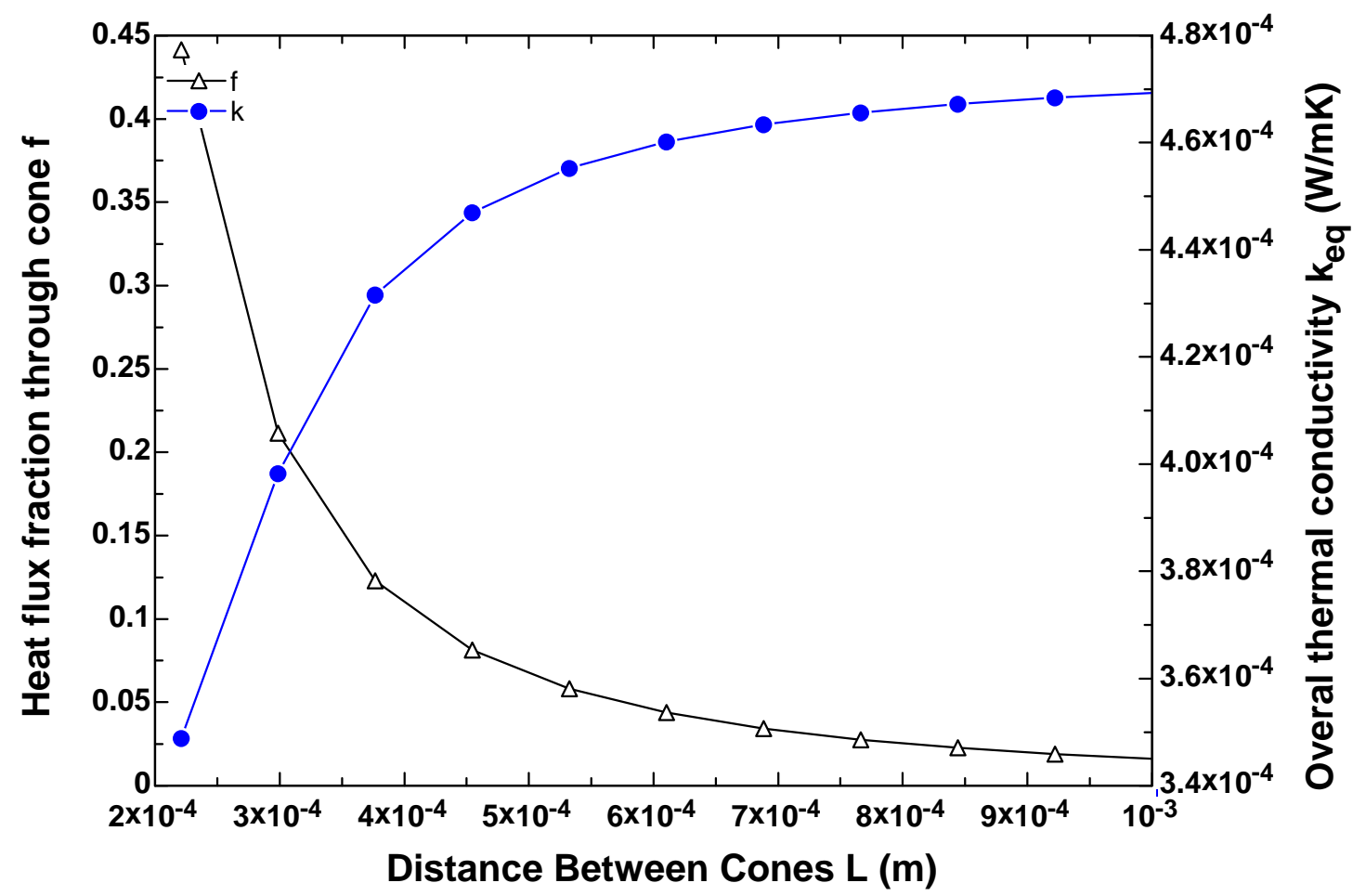

Figure 7: Heat Flux Fraction as a Function of Distance between Cones

As can be seen, cone separations on the order of a few hundred microns are needed to ensure that the heat transfer is dominated by the area between the cones.

The gas conduction is independent of distance between the two plates $\mathrm{D}$, however, the heat conduction through the cones decreases and the overall thermal conductivity increases as the $\mathrm{D}$ becomes larger. When $\mathrm{L}=5 * 10^{-4} \mathrm{~m}, \mathrm{P}=5$ Torr, the relationship of $\mathrm{D}$ and $\mathrm{f}, \mathrm{k}_{\mathrm{eq}}$ are given below. 


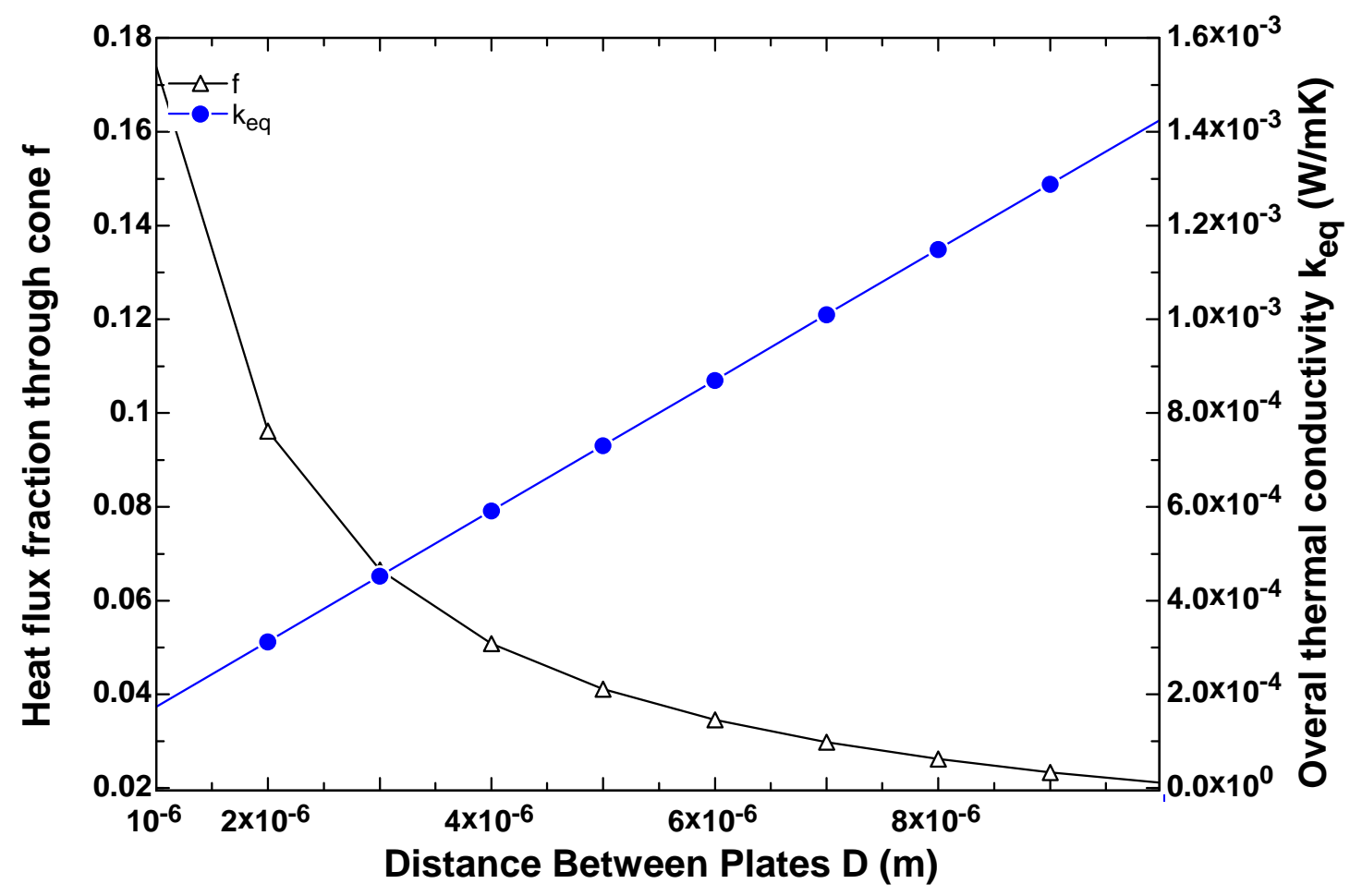

Figure 8: Dependence of Fraction of Heat Transfer Through Cones as a Function of Plate Separation

\section{Monte Carlo Heat Transport}

To better model the radiation through the MHB, we have begun development of a Monte Carlo photon transport code to allow us to assess the importance of radiation from the cones. The geometry of the model is shown below 


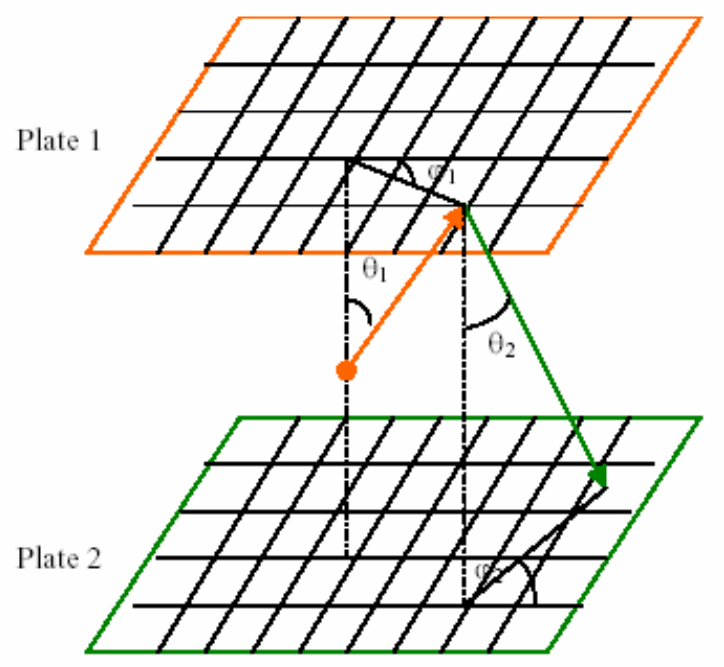

Figure 9: Schematic of Monte Carlo Model

This figure shows a source between two plates and one reflection of a photon off of one plate, towards the second. The surfaces can be modeled as either specular or diffuse. The figure below shows a typical set of intensity contours on the second plate, due to a fan-shaped source reflecting off of both a specular and diffuse first plate. Development of these models is in progress and will help us to better understand heat transfer in the MHB.

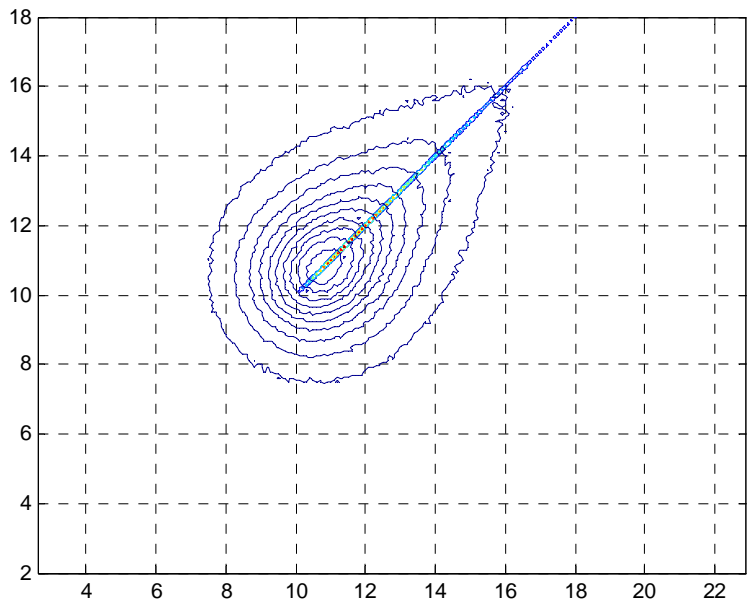

Figure 10: Intensity Contours on Lower Plate Due to Both Specular and Diffuse Reflection 


\section{Thermionic Battery Design}

A preliminary thermionic battery design was carried out using the following assumptions:

- Heat source: Po-210

- Source geometry: right cylinder DxH=200x200 microns

- $\quad$ Specific activity $=4541 \mathrm{Ci} / \mathrm{gram}$

- Density of Po $9200 \mathrm{~g} / \mathrm{cm}^{3}$

- $\quad$ Maximum activity $=0.26 \mathrm{Ci}$

- $\quad$ Assume activity $=0.25 \mathrm{Ci}$

- Assume the source is homogeneous and has a uniform temperature $\mathrm{T}_{0}$

- The environment temperature $\mathrm{T}_{\infty}=300 \mathrm{~K}$

Heat loss through top MHB and GaAs layer

The key to the battery design is a thorough understanding of the heat loss mechanisms and magnitudes. To begin, we estimate the heat loss through the top of the MHB, assuming that the thickness of top GaAs layer is 100 microns, the thermal conductivity of GaAs is $40 \mathrm{~W} / \mathrm{m} / \mathrm{K}$, and the thermal conductivity of the MHB is assumed to be $0.0002 \mathrm{~W} / \mathrm{m}-\mathrm{K}$.

The heat loss through the top layer can be modeled as

$$
\begin{aligned}
& Q_{\text {top }}=A_{\text {top }} \frac{k_{\text {GaAs }}}{\delta_{\text {GaAs }}}\left(T_{\text {top }}-T_{\infty}\right) \\
& Q_{\text {top }}=\frac{k_{M H B}}{\delta_{M H B}} A_{\text {top }}\left(T_{0}-T_{\text {top }}\right)
\end{aligned}
$$

where $\mathrm{T}_{\text {top }}$ is the temperature of the top surface of the MHB and $\mathrm{Q}_{\mathrm{top}}$ is the heat flux per unit cathode area lost through the top MHB.

Heat loss through bottom MHB, Helium plenum and bottom GaAs layer

The heat loss through the bottom layer is modeled assuming the thickness of the Helium plenum is 100 microns, the thickness of the bottom GaAs layer is 100 microns, and the thermal conductivity of Helium is $0.152 \mathrm{~W} / \mathrm{m} / \mathrm{K}$.

The heat loss here is modeled as 


$$
\begin{gathered}
Q_{\text {bottom }}=A_{\text {bottom }}\left(\frac{k_{H e}}{\delta_{H e}}+\frac{k_{\text {GaAs }}}{\delta_{\text {GaAs }}}\right)\left(T_{\text {bottom }}-T_{\infty}\right) \\
Q_{\text {bottom }}=\frac{k_{M H B}}{\delta_{M H B}} A_{\text {bottom }}\left(T_{0}-T_{\text {bottom }}\right)
\end{gathered}
$$

where $\mathrm{T}_{\text {bottom }}$ is the temperature of the outside bottom surface of the MHB and $\mathrm{Q}_{\text {bottom }}$ is the heat flux per unit cathode area lost through the bottom MHB.

Heat radiation and conduction loss through the gap between cathode and anode

To estimate losses through the cathode/anode gap, we assume the gap vacuum is 0.01 torr, so gas conduction is negligible, and the side GaAs wall thickness is 200 microns. The cathode and anode emissivities are assumed to be $1 / 3$ and $2 / 3$, respectively. If the cathode temperature matches the source temperature, then we can model the side losses as:

$$
Q_{\text {side }}=A_{c} \frac{k_{\text {GaAs }}}{\delta_{\text {GaAs }}}\left(T_{\text {anode }}-T_{\infty}\right)
$$

and

$$
Q_{\text {side }}=\sigma \cdot A_{c}\left[\frac{T_{0}{ }^{4}-T_{\text {anode }}{ }^{4}}{\frac{1}{\varepsilon_{\text {anode }}}+\frac{1}{\varepsilon_{\text {cathode }}}-1}\right]
$$

Heat loss by conduction from the cathode through the electrical lead to the load

To reduce conduction losses, a low thermal conductivity and thin lead should be chosen. In this case, assuming the thermal conductivity of the copper lead $\mathrm{k}_{\text {lead }}$ is $400 \mathrm{~W} / \mathrm{m} / \mathrm{K}$, the thermal conductivity of the iron lead $\mathrm{k}_{\text {lead }}$ is $60 \mathrm{~W} / \mathrm{m} / \mathrm{K}$, and the length of the lead $\mathrm{L}$ is 100 microns. This gives the conduction losses to the leads as:

$$
Q_{\text {cond }}=k_{\text {lead }} A_{\text {lead }} \frac{T_{0}-T_{\infty}}{L}
$$

Heat dissipated through the electrical lead by Joule heat

Half of the loss flows toward the cathode and the other half flows toward the load. If $I_{n}$ is the electron current density emitted by the cathode and the cathode material is BaSrO Scandate, the joule losses are

$$
Q_{\text {joule }}=\left(I_{n} A_{c}\right)^{2} R_{\text {lead }}
$$


where $\mathrm{R}$ is the electrical resistance of the Titanium lead, given by

$$
R_{\text {lead }}=\rho_{\text {lead }} \frac{L_{\text {lead }}}{A_{\text {lead }}}
$$

Using the electrical resistivity of copper as lead $=1.72 \times 10^{-8} \quad$ ohm-m and the electrical resistivity of iron as ${ }^{\text {pead }}=9.71 \times 10^{-8} \quad$ ohm-m, and using the Wideman-Franz law, the product of the electrical resistivity and the thermal conductivity are a direct function of temperature:

$$
\rho_{\text {lead }} k_{\text {lead }}=\frac{\pi^{2}}{3}\left(\frac{k}{e}\right)^{2} T_{\text {lead }}
$$

where $\mathrm{k}$ is the Boltzmann constant, $e$ is the charge on the electron, and $\mathrm{T}_{\text {lead }}$ is the lead temperature. The combined conduction and joule losses per unit cathode area are given by

$$
Q_{\text {cond }, \text { joule }}=\frac{\pi^{2}}{6}\left(\frac{k}{e}\right)^{2} \frac{\left(T_{0}^{2}-T_{\infty}^{2}\right)}{R_{\text {lead }}}-\frac{1}{2} I_{n}^{2} A_{c}^{2} R_{\text {lead }}
$$

\section{Electron energy}

If $Q_{e}$ is the energy electrons needed to escape from the cathode and reach the anode, that is, the potential energy imparted to the electrons plus their average kinetic energy at the cathode temperature, then the electron energy is

$$
Q_{e}=I_{n} A_{c}\left(\Delta V_{c}+\frac{2 k T_{0}}{e}\right)
$$

where

$$
\Delta V_{c}=\Delta V_{a}+\Delta V_{L}+\Delta V_{\text {lead }}
$$

The total energy balance is

$$
Q_{\text {top }}+Q_{\text {bottom }}+Q_{\text {side }}+Q_{\text {cond }}-\frac{Q_{\text {joule }}}{2}+Q_{e}=Q
$$

The efficiency of the battery is defined as

$$
\eta=\frac{Q_{L}}{Q}
$$

where $\mathrm{Q}_{\mathrm{L}}$ is the useful load power per unit cathode area

$$
Q_{L}=I_{n} A_{c} \Delta V_{L}
$$

The efficiency is written by combining 


$$
\eta=\frac{I_{n} A_{c} \Delta V_{L}}{Q_{\text {top }}+Q_{\text {bottom }}+Q_{\text {side }}+I_{n} A_{c}\left(\Delta V_{a}+\Delta V_{L}+\Delta V_{\text {lead }}+\frac{2 k T_{0}}{e}\right)+\left[\frac{\pi^{2}}{6}\left(\frac{k}{e}\right)^{2} \frac{\left(T_{0}^{2}-T_{\infty}{ }^{2}\right)}{R_{\text {lead }}}-\frac{1}{2} I_{n}{ }^{2} A_{c}{ }^{2} R_{\text {lead }}\right]}
$$

The efficiency is maximized with respect to $R_{\text {lead }}$ and $R_{L}$ by obtaining the derivatives of $1 / \eta$ with respect to these quantities and equating to zero.

$$
\frac{\partial\left(\frac{1}{\eta}\right)}{\partial R_{\text {lead }}}=0 \text { and } \frac{\partial\left(\frac{1}{\eta}\right)}{\partial R_{L}}=0
$$

The results

$$
\begin{gathered}
R_{\text {lead }}=\frac{1}{\left(Q_{\text {top }}+Q_{\text {bottom }}+Q_{\text {side }}\right)}\left(\frac{k T_{0}}{e}\right)^{2}\left[\frac{\pi \cdot \Gamma}{\sqrt{\frac{3}{2}+3 \Gamma}}\right] \\
R_{L}=\frac{1}{\left(Q_{\text {top }}+Q_{\text {bottom }}+Q_{\text {side }}\right)}\left(\frac{k T_{0}}{e}\right)^{2}\left[2+\frac{\Delta V_{a} e}{k T_{0}}+\Gamma+\frac{\pi(1+\Gamma)}{\sqrt{\frac{3}{2}+3 \Gamma}}\right] \\
\Gamma=\frac{\left(Q_{\text {top }}+Q_{\text {bottom }}+Q_{\text {side }}\right) e}{k T_{0} \cdot A_{c}} \cdot \frac{1}{\Gamma} \\
\ln \left(\frac{\Delta V_{a} e}{\left(T_{0} k\right.}+2+\pi \sqrt{\frac{2}{3}(1+2 \Gamma)}\right.
\end{gathered}
$$

\section{Final Design}

Our final design parameters include a source activity of $0.25 \mathrm{Ci}$, MHB thermal conductivity of $5 \mathrm{e}-5 \mathrm{~W} / \mathrm{m}^{2} \mathrm{~K}$, potential difference between the collector Fermi level and the interelectrode minimum $\Delta V_{a}$ of 1 volt, emittance of emitter and collector surface of 0.333 and 0.667 , respectively, Richardson constant of $10^{6} \mathrm{amp} / \mathrm{m}^{2} \mathrm{~K}$, output current of $1.12 \mathrm{~mA}$ output voltage of 0.18 volts, output power of $2 \times 10^{-4} \mathrm{~W}$, source temperature of $781 \mathrm{~K}$. In this design, $57 \%$ of the energy is used to supply potential and kinetic energy to electrons, $28 \%$ energy is lost through the gap between emitter and collector, 5.6\% through the top MHB, 5.6\% through the bottom MHB, and 4\% through the copper electrical lead. 
The output power, current and conversion efficiency increase with the decrease of $\Delta V_{a}$. This is because the $\Delta V_{L}$ increases with the $\Delta V_{a}$ decreases, which gives more useful load power.

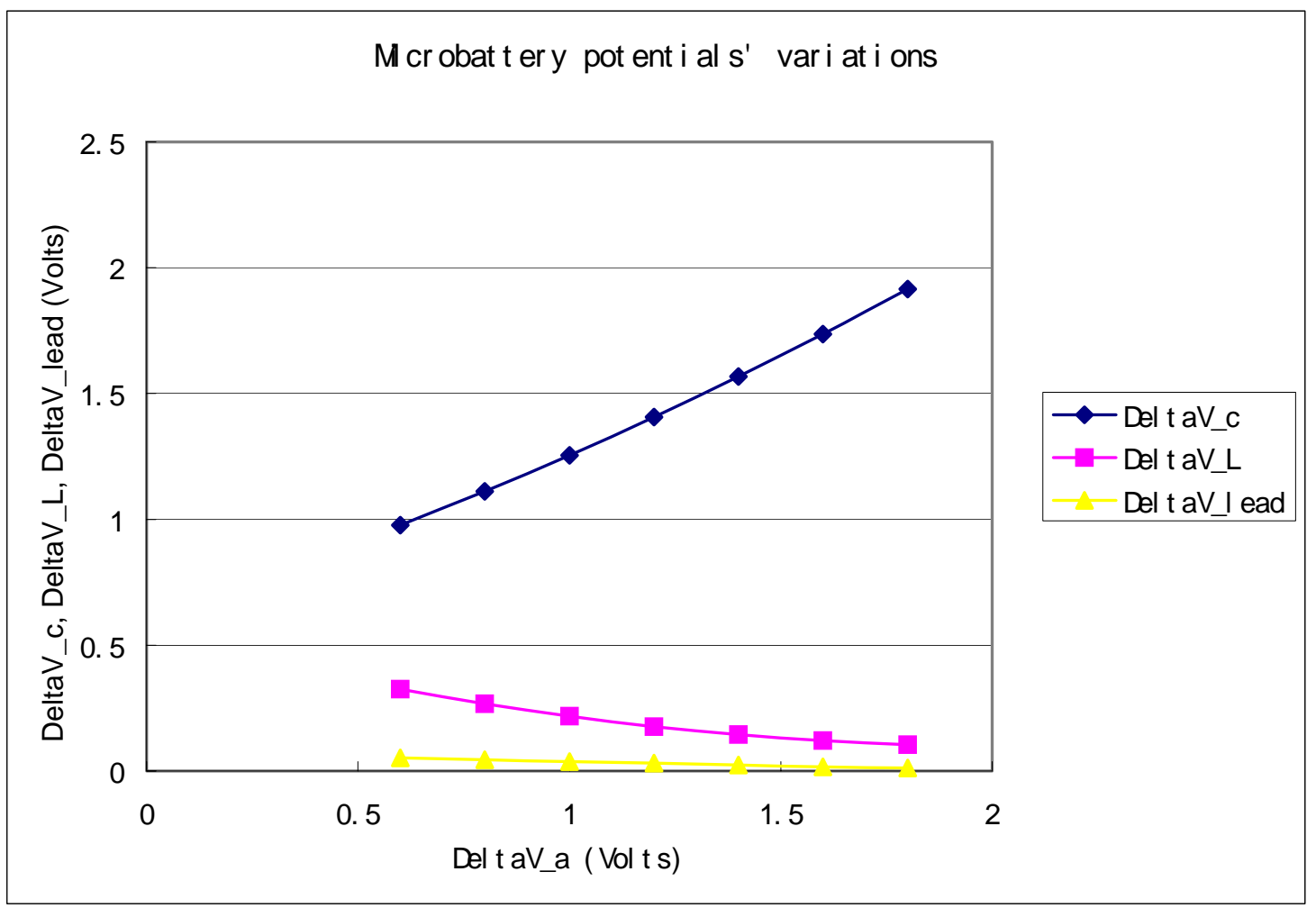

The thermal conductivity of the MHBs is critical in determining the performance of the microbattery. When $\mathrm{k}_{\mathrm{MHB}}$ is $10^{-5}$ or $10^{-6} \mathrm{~W} / \mathrm{mK}$, the differences in the performance are less significant than those around the order of $10^{-4}$ and $10^{-5} \mathrm{~W} / \mathrm{mK}$. Thus the goal of the MHB's thermal conductivity should around the order of $10^{-5} \mathrm{~W} / \mathrm{mK}$. 

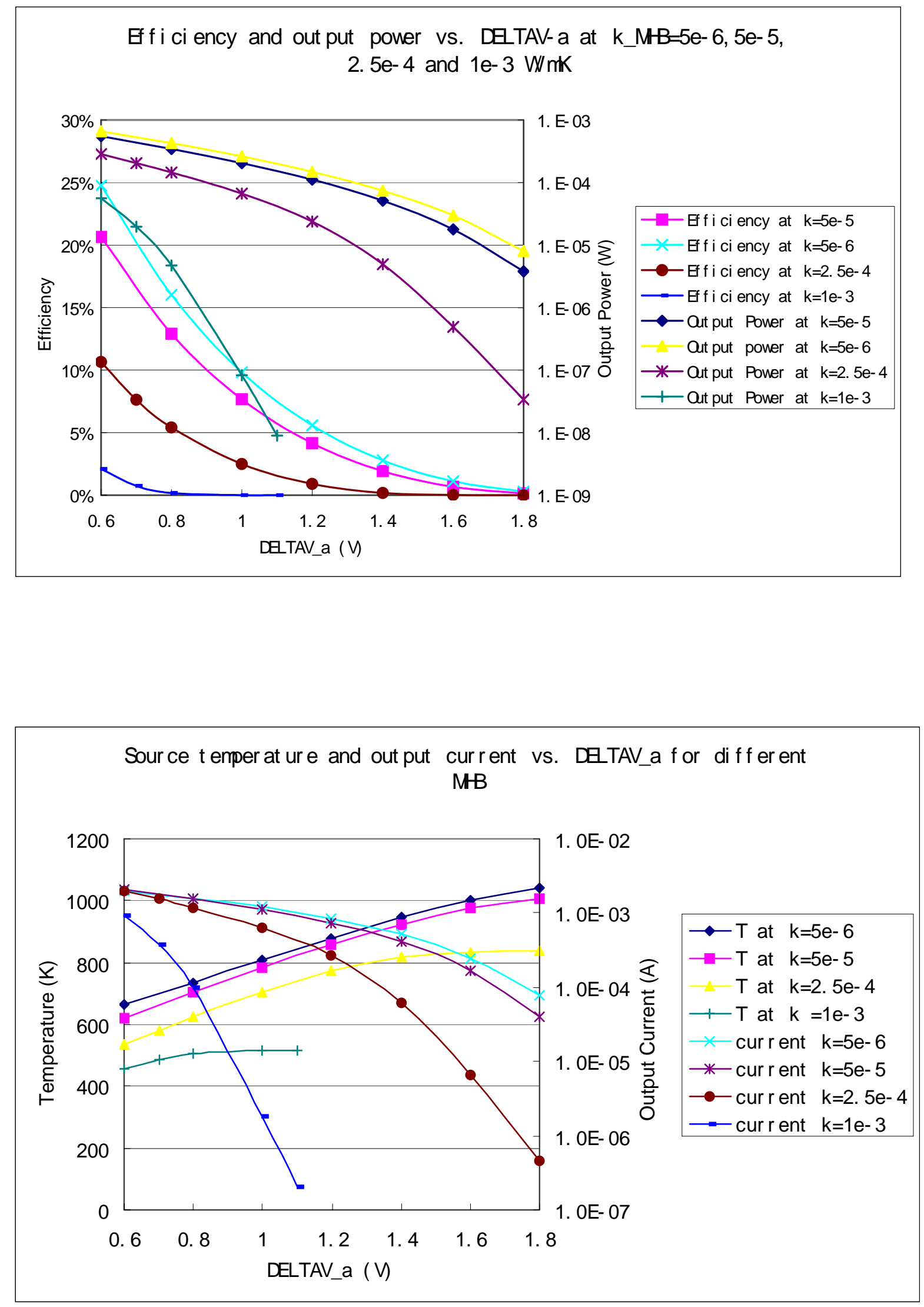
The emittances of the cathode and anode surfaces also affect the battery's performance. The lower the emittance, the less heat loss through the interelectrode gap, and the higher the output power and the efficiency.

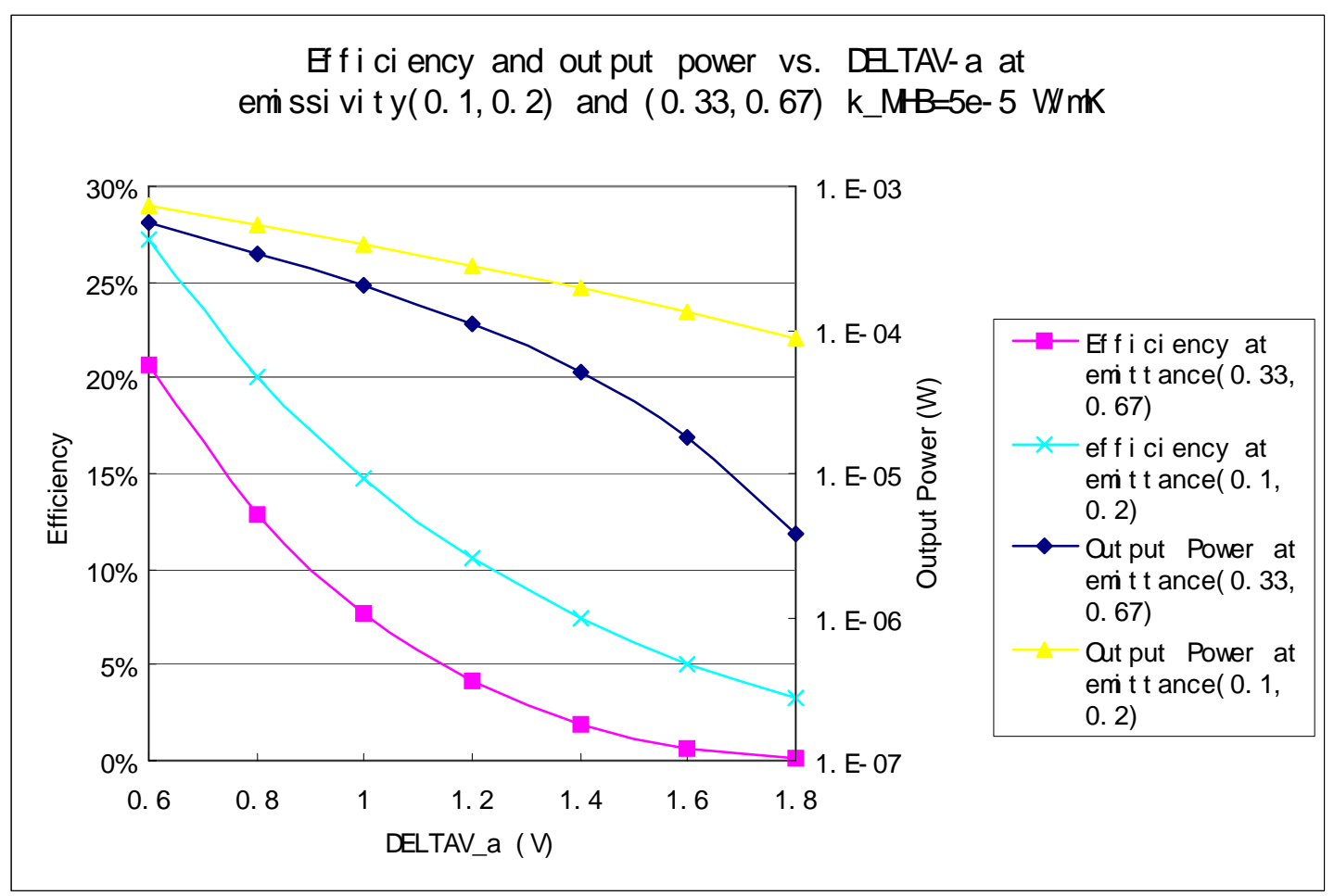




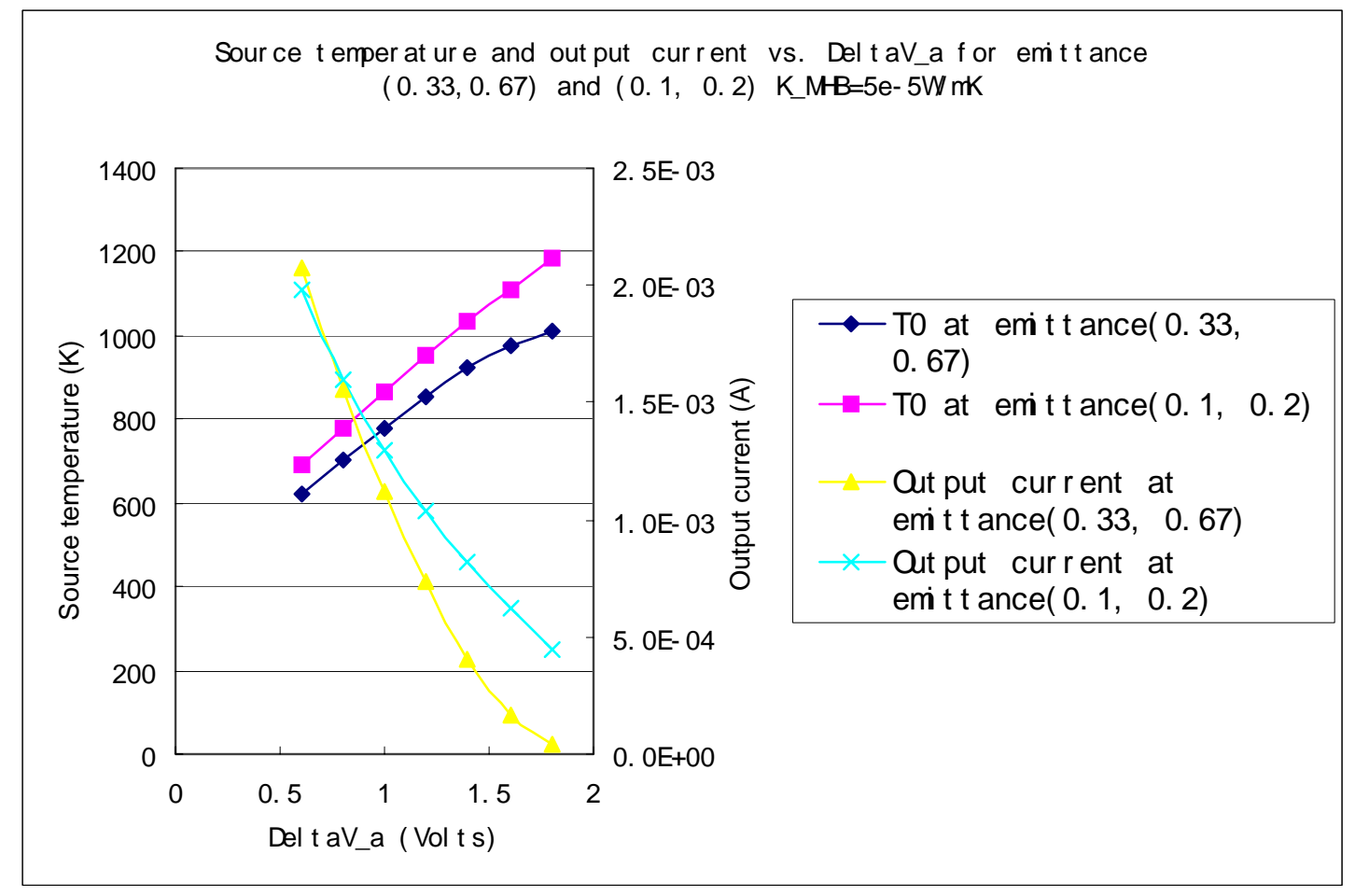

The electrical lead material has little impact on the battery. For a copper lead with electrical conductivity $1.72 \mathrm{e}-8 \mathrm{ohm} . \mathrm{m}$, and thermal conductivity $400 \mathrm{~W} / \mathrm{mK}$, and an iron lead with electrical conductivity $9.71 \mathrm{e}-8 \mathrm{ohm} . \mathrm{m}$, and thermal conductivity $60 \mathrm{~W} / \mathrm{mK}$, the output power and conversion efficiency have very minimum difference.

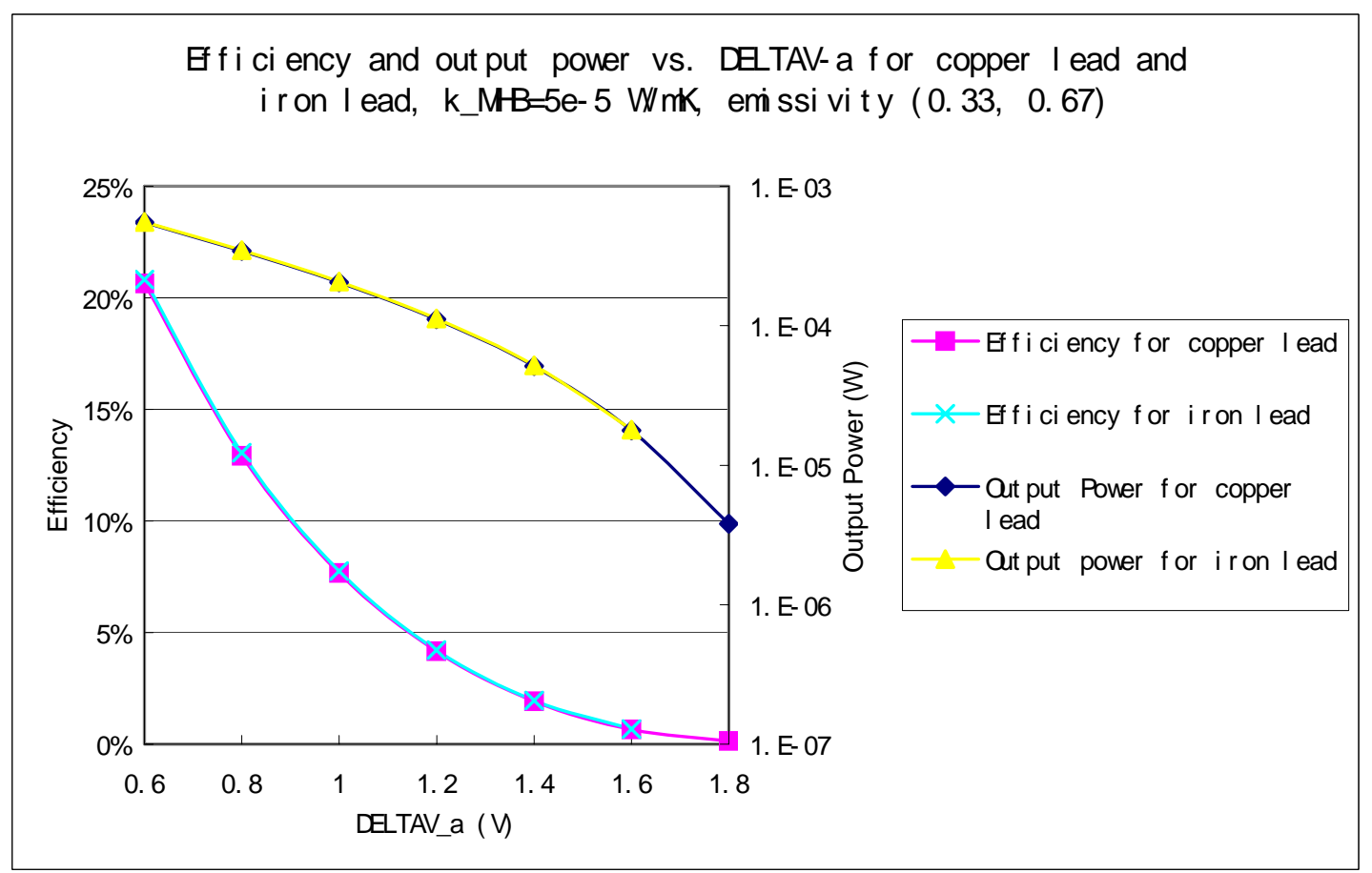


The Richardson constants of different materials vary dramatically. Hasker and Van Dorst demonstrated that alkali earth $(\mathrm{BaSrCaO})$ electrodes incorporating a scandate capping layer result in work functions as low as $1.0 \mathrm{eV}$ with apparent emission constants of about $10^{5} \mathrm{amp} / \mathrm{m}^{2} \mathrm{~K}^{2}$. Zavadil, Ruffner and King incorporated $\mathrm{BaSrO}$ into a $\mathrm{Sc}_{2} \mathrm{O}_{3}$ matrix using rf sputtering to produce thin film cathode. The maximum work function is $1.8 \mathrm{eV}$ and an apparent emission constant is $360 \mathrm{amp} / \mathrm{m}^{2} \mathrm{~K}^{2}$. [31]

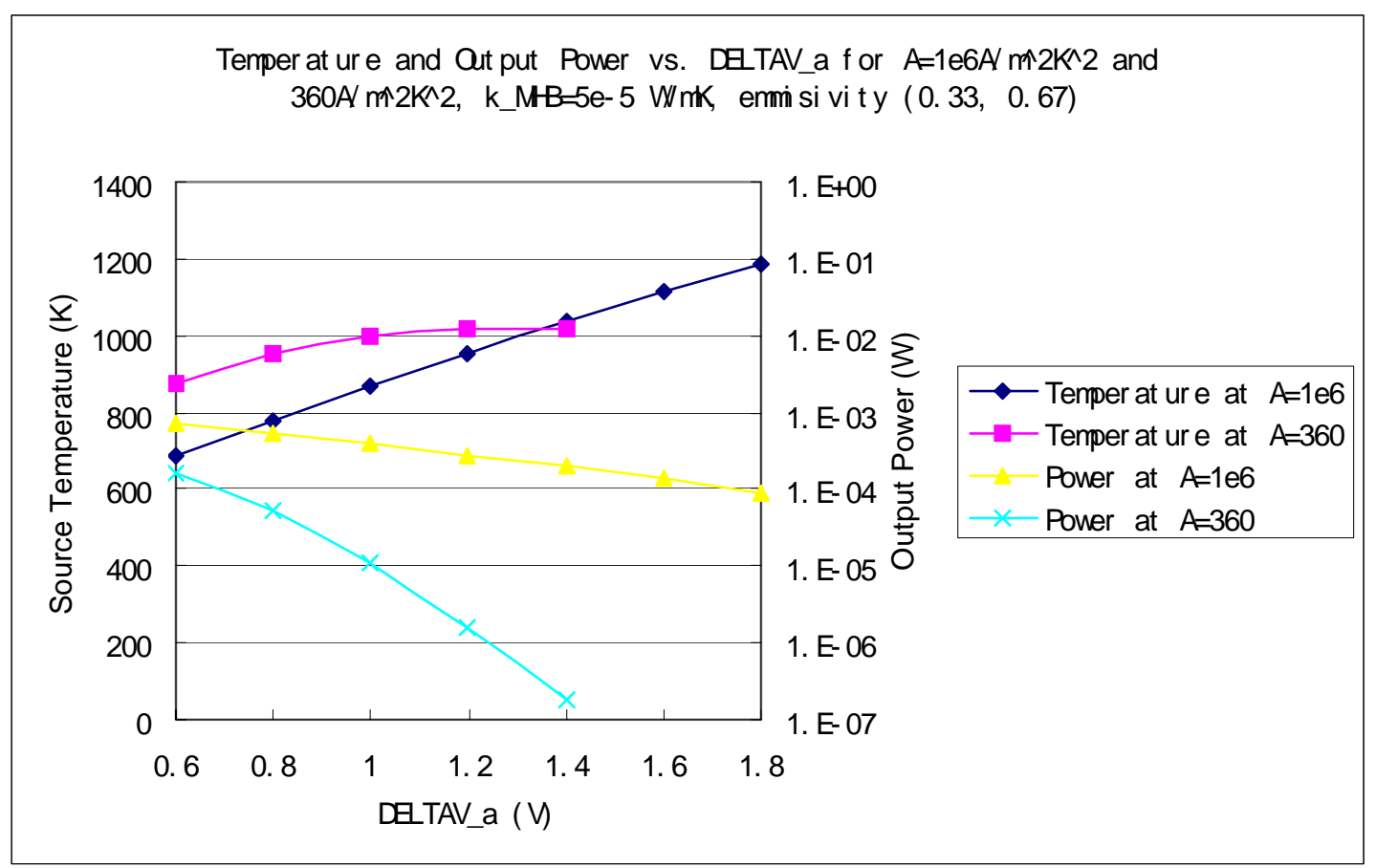

